\title{
Optimisation of dark adaptation time required for mesopic microperimetry
}

\author{
RC Han (1, 2), JM Gray (2), J Han (3), RE MacLaren (1, 2), JK Jolly (1, 2)* \\ 1 Oxford Eye Hospital, John Radcliffe Hospital, Oxford, United Kingdom \\ 2 Nuffield Laboratory of Ophthalmology, Nuffield Department of Clinical Neurosciences, \\ University of Oxford, Oxford, United Kingdom \\ 3 Oxford Medical School, Oxford University, Oxford, United Kingdom \\ *Corresponding author: enquiries@ndcn.ox.ac.uk \\ Postal address: Oxford Eye Hospital, John Radcliffe Hospital, Oxford, United Kingdom
}




\section{SYNOPSIS}

This paper provides evidence-based guidance for duration of dark adaptation required for MAIA microperimetry testing in future clinical and research settings. This paper also provides evidence for cone-mediated central retinal responses under mesopic conditions. 


\section{ABSTRACT}

\section{Background}

Macular Integrity Assessment (MAIA) microperimetry is increasingly used in clinical and research settings to assess point retinal sensitivity and fixation stability. Testing occurs under mesopic conditions, commonly after a period of dark adaptation. Our aim was to identify the minimum length of adaptation required to optimise microperimetry performance.

\section{Methods}

MAIA microperimetry using the 10-2 grid was performed on 40 right eyes of 40 healthy participants aged 18-73 with no ocular pathology and vision of at least 0.1LogMAR after ambient light exposure, with $0,5,10,15,20$ and 30 minutes of adaptation in mesopic settings. Ten right eyes of 10 participants with choroideremia were also tested following 0 and 20 minutes of adaptation. We further tested 10 right eyes of 10 healthy participants after bright light exposure, with 0,10 and 20 minutes of adaptation. We compared changes in threshold sensitivity and fixation stability across time points.

\section{Results}

Microperimetry performance did not improve with increasing adaptation time in healthy participants or choroideremia patients after ambient light exposure. After bright light exposure, we found microperimetry thresholds improved after 10 minutes of adaptation, but did not improve further at 20 minutes.

\section{Conclusion}

Mesopic adaptation is not required before MAIA microperimetry after exposure to ambient light. Ten minutes of adaptation is sufficient after exposure to a bright light stimulus, such as ophthalmoscopy or retinal imaging. The brief time of dark adaptation required corresponds to cone adaptation curves and provides further evidence for cone-mediated central retinal function under mesopic conditions. 


\section{INTRODUCTION}

Microperimetry is increasingly used in both clinical and research settings as a highly sensitive measure of functional change in conditions as diverse as diabetic maculopathy, age-related macular degeneration, glaucoma, pathological myopia, vitreoretinal disorders and inherited retinal dystrophies (1-6). A number of mesopic microperimeters are in clinical use, including the MP-3 and MP-1S (Nidek, Italy), the OCT-SLO (OPKO, Miami, USA), and the MAIA (Centervue, Padova, Italy). These microperimeters assess function under mesopic conditions by mapping retinal perceptual thresholds to projected point light stimuli, and by measuring fixation stability. In the Oxford Eye Hospital, the MAIA microperimeter is in clinical and research use. It operates with a background illumination of $1.3 \mathrm{~cd} / \mathrm{m}^{2}$, and presents white point (Goldman size III) stimuli to the central 10 degrees of visual field (7).

It is well known that retinal sensitivity to light stimuli improves with dark adaptation after a period of bleaching or bright light exposure. Due to the physiological requirements of regeneration of rhodopsin and cone opsins, rods recover their maximum sensitivity after bleaching in 20 minutes, while cones recover in 5-8 minutes (8). Thus a period of dark adaptation before MAIA microperimetry was proposed to maximise photoreceptor sensitivity (8). It has been previously proposed that mesopic microperimetry may measure both cone and rod responses (9). In the Oxford Eye Hospital, therefore, dark adaptation was set at 20 minutes, justified with reference to historical data based on rod photoreceptor physiology and the human visual cycle $(5,10)$.

Recent research examining central retinal spectral sensitivities, however, has suggested that in humans, mesopic microperimetry responses to size III Goldman size stimuli appear to be mediated predominantly by $\mathrm{M} / \mathrm{L}$ and $\mathrm{S}$ cones in the central $\left(9^{0}\right)$ visual field, while there is a mixed $\mathrm{M} / \mathrm{L}$ cone and rod response peripherally (11). Given the marked difference in adaptation time between rods and cones, this has significant implications for the adaptation time required before mesopic microperimetry testing of the central visual field.

Optimising dark adaptation time allows for standardisation of the microperimetry operation protocol, enabling more meaningful comparison of results across studies. Currently studies 
show little consistency across different centres, which hinders interpretation. A literature search on PubMED shows a wide variety of practices regarding dark adaptation. Out of 20 randomly selected papers using mesopic microperimetry, 13 did not mention adaptation time, 2 used no adaptation time, 2 used 'at least 5 minutes', 2 'at least 10 minutes' and 2 'at least 15 minutes' and '20 minutes' respectively. Furthermore, there clearly exists debate and uncertainty within the literature as to how much microperimetry performance is affected by dark adaptation, if at all. A recent paper by Wu et al (3) examining the learning effect on microperimetry performance exemplifies the current uncertainty when they note that previous reports have "found higher retinal sensitivities in the second eye tested within the same session after assessment of both eyes" and this was interpreted as "adaptation to the low background luminance of the microperimeter $\left(1.27 \mathrm{~cd} / \mathrm{m}^{2}\right)$ may be responsible for this observation" and hence, "to avoid the effects of adaptation, we ensured that each test was performed under identical settings by turning on the room lighting following each test." Clarifying the optimal time for dark adaptation may reduce time burden in clinic and on patients. It also provides a starting point for further research into adaptation for disease states and in sub-populations such as the elderly. The aim of this project therefore was examine the relationship between length of dark adaptation and retinal thresholds as well as fixation stability for mesopic microperimeter. 


\section{MATERIALS AND METHODS}

Testing was carried out using a MAIA microperimeter at the Oxford Eye Hospital (Oxford, United Kingdom). Oxford Central University Ethics Research Committee granted ethics approval (R43588/RE001).

Healthy participants with best-corrected visual acuity of 0.1 LogMar or better in the right eye and no co-existing pathology were recruited from the University of Oxford medical sciences department advertising portals. We recruited 40 healthy adults to attend for multiple tests over 2 days.

Prior to testing, all "microperimetry-naïve" participants first underwent two learning fields in the right eye. This was to minimise the confounding impact of any learning effect. The final test configuration for all patients was a 37 point grid (with 4-2-1 staircase strategy), in 3 concentric circles of 2, 6 and 10 degrees of diameter centred on the fovea. All dark adaptation was carried out in mesopic conditions ( $<1$ lux). MAIA measures false positives using percentage fixation losses. We did not have any exclusion criteria for unreliable tests as we were concerned that, due to higher fixation instability in choroideremia patients, this may lead to excessive repetition of measurements which would increase participant fatigue without improving data quality.

We assessed 40 right eyes of 40 healthy individuals with adaptation times of $0,5,10,15,20$ and 30 minutes prior to each test. Subjects were exposed to 5 minutes of ambient room light in between each test. Subjects were not dilated prior to microperimetry testing (12). Testing was carried out in 2 sessions no longer than 1 week apart to minimise fatigue.

Additionally we assessed 10 right eyes of 10 participants with choroideremia after exposure to ambient room light, with 0 and 20 minutes of adaptation. Choroideremia is an X-linked retinal disease characterised by rod-cone degeneration that has been well characterised previously (5). It was chosen for comparison to allow the impact of adaptation on a degenerate retina which has good central cone function but severe rod impairment to be effectively assessed. Hence any difference relating to cone function only might be more apparent in the choroideremia patient subgroup. 0 and 20 minutes were chosen after completion of testing of healthy participants for the following reasons: firstly, standard dark adaptation time in the Oxford Eye Hospital is 20 minutes, based on rod adaptation times; 
and secondly, the work on healthy participants had suggested no effect of dark adaptation (see Results below). We therefore chose only 0 and 20 minutes for the choroideremia group to help reduce testing burden on the patients. Results were analysed in the same way as for the healthy participants. Finally, we assessed 10 right eyes of 10 healthy individuals after exposure to 3 minutes of direct ophthalmoscopy, with 0,10 and 20 minutes of adaptation to simulate conditions following an ophthalmic examination or ophthalmic imaging. 0,10 , and 20 minutes were chosen for the following reasons; firstly, 0 minutes acted as a baseline; subsequently, cones would be expected to reach maximum sensitivity at 10 minutes, and finally cones would be expected to reach maximum sensitivity at 20 minutes, and as a comparator to the 20 minute time point in both the healthy participant and choroideremia groups.

The primary outcome measure was the effect of length of adaptation on microperimetery, defined by difference in average threshold sensitivity and fixation stability between baseline and repeat testing. The difference in threshold sensitivity between the baseline and repeat tests was calculated with a positive value indicating an increase in sensitivity and a negative value indicating a decrease in sensitivity. Differences in fixation stability as represented by the log 95\% fixation area (represented by the bivariate contour ellipse area, or log BCEA) were calculated between the tests, with a positive value indicating a decrease in fixation stability i.e. larger BCEA and negative value indicating an increase in fixation stability i.e. smaller BCEA. The time points were compared using a mixed effects linear model, with individual eyes chosen as a random effect. Data were tested for normality using the Shapiro Wilk function, and modelling undertaken using the linear mixed effects function from the non-linear mixed effects package in $R$ studio (Version 1.0.44, supported by $R$ version 3.2.2.). All data were found to be normally distributed. Confidence intervals were found using the semi-parametric boostrapping package in R studio. Figure 3 was created using FME (Safe Software Inc, British Columbia, Canada) and QGIS (version 2.18, Free Software Foundation Inc, MA, USA). 


\section{RESULTS}

The characteristics of our test groups are summarised in Table 1. In both healthy participants and in choroideremia patients, we found that there was no clinically significant difference in either threshold or fixation stability with increasing length of dark adaptation after exposure to ambient light (Table 2).

\begin{tabular}{|c|c|c|c|c|c|c|}
\hline Characteristics & \multicolumn{2}{|c|}{$\begin{array}{l}\text { Healthy participants } \\
\text { (ambient light cohort) }\end{array}$} & \multicolumn{2}{|c|}{$\begin{array}{l}\text { Choroideremia } \\
\text { patients }\end{array}$} & \multicolumn{2}{|c|}{$\begin{array}{l}\text { Healthy participants } \\
\text { (bright light cohort) }\end{array}$} \\
\hline$N$ & \multicolumn{2}{|l|}{40} & \multicolumn{2}{|l|}{10} & \multicolumn{2}{|l|}{10} \\
\hline $\begin{array}{l}\text { Age range } \\
\text { (mean, } \pm \\
\text { standard } \\
\text { deviation) in } \\
\text { years }\end{array}$ & \multicolumn{2}{|c|}{$18-73(33 \pm 15)$} & \multicolumn{2}{|c|}{$17-63(39 \pm 14)$} & \multicolumn{2}{|c|}{$22-40(31 \pm 6)$} \\
\hline Male/female & \multicolumn{2}{|l|}{$16 / 24$} & \multicolumn{2}{|l|}{$10 / 0$} & \multicolumn{2}{|l|}{$3 / 7$} \\
\hline \multirow[t]{2}{*}{$\begin{array}{l}\text { Adaptation } \\
\text { time (minutes) }\end{array}$} & \multicolumn{2}{|c|}{$\begin{array}{l}\text { Healthy participants } \\
\text { (ambient light cohort) } \\
\text { Value shown } \pm \text { standard } \\
\text { error }\end{array}$} & \multicolumn{2}{|c|}{$\begin{array}{l}\text { Choroideremia } \\
\text { patients } \\
\text { Value shown } \pm \\
\text { standard error }\end{array}$} & \multicolumn{2}{|c|}{$\begin{array}{l}\text { Healthy participants } \\
\text { (bright light cohort) } \\
\text { Value shown } \pm \text { standard } \\
\text { error }\end{array}$} \\
\hline & $\begin{array}{l}\text { Sensitivity } \\
\text { thresholds } \\
\text { (dB) }\end{array}$ & $\begin{array}{l}\text { Fixation } \\
\text { areas } \\
\text { (logBCEA) }\end{array}$ & $\begin{array}{l}\text { Sensitivi } \\
\text { ty } \\
\text { threshol } \\
\text { ds (dB) }\end{array}$ & $\begin{array}{l}\text { Fixation } \\
\text { areas } \\
(\log B C E \\
\text { A) }\end{array}$ & $\begin{array}{l}\text { Sensitivity } \\
\text { thresholds } \\
\text { (dB) }\end{array}$ & $\begin{array}{l}\text { Fixation } \\
\text { areas } \\
(\log B C E A)\end{array}$ \\
\hline 0 & $\begin{array}{l}28.48 \pm \\
0.19\end{array}$ & $0.28 \pm 0.06$ & $\begin{array}{l}7.80 \pm \\
2.27\end{array}$ & $\begin{array}{l}0.22 \pm \\
0.22\end{array}$ & $\begin{array}{l}28.16 \pm \\
0.88\end{array}$ & $-0.31 \pm 0.33$ \\
\hline
\end{tabular}




\begin{tabular}{|c|c|c|c|c|c|c|}
\hline 5 & $\begin{array}{l}28.57 \pm \\
0.19\end{array}$ & $0.34 \pm 0.06$ & & & & \\
\hline 10 & $\begin{array}{l}28.76 \pm \\
0.19\end{array}$ & $0.23 \pm 0.06$ & & & $\begin{array}{l}29.28 \pm \\
0.90\end{array}$ & $0.24 \pm 0.35$ \\
\hline 15 & $\begin{array}{l}28.37 \pm \\
0.21\end{array}$ & $\begin{array}{l}-0.31 \pm \\
0.05\end{array}$ & & & & \\
\hline 20 & $\begin{array}{l}28.58 \pm \\
0.22\end{array}$ & $\begin{array}{l}-0.28 \pm \\
0.06\end{array}$ & $\begin{array}{l}7.62 \pm \\
2.36\end{array}$ & $\begin{array}{l}0.30 \pm \\
0.19\end{array}$ & $\begin{array}{l}29.13 \pm \\
1.00\end{array}$ & $0.25 \pm 0.37$ \\
\hline 30 & $\begin{array}{l}28.61 \pm \\
0.20\end{array}$ & $\begin{array}{l}-0.21 \pm \\
0.40\end{array}$ & & & & \\
\hline
\end{tabular}

Table 1. Characteristics of study population and results of average sensitivity and fixation area as measured for each time point.

\begin{tabular}{|c|c|c|c|c|c|c|}
\hline \multirow[t]{2}{*}{ Adaptation times } & \multicolumn{2}{|c|}{$\begin{array}{l}\text { Healthy participants } \\
\text { (ambient light group) }\end{array}$} & \multicolumn{2}{|c|}{$\begin{array}{l}\text { Choroideremia } \\
\text { patients (ambient } \\
\text { light) }\end{array}$} & \multicolumn{2}{|c|}{$\begin{array}{l}\text { Healthy participants } \\
\text { (bright light group) }\end{array}$} \\
\hline & $\begin{array}{l}\text { Sensitivity } \\
\text { thresholds } \\
\text { (dB) }\end{array}$ & $\begin{array}{l}\text { Fixation } \\
\text { areas } \\
(\log B C E A)\end{array}$ & $\begin{array}{l}\text { Sensitivity } \\
\text { thresholds } \\
\text { (dB) }\end{array}$ & $\begin{array}{l}\text { Fixation } \\
\text { areas } \\
\text { (logBCEA) }\end{array}$ & $\begin{array}{l}\text { Sensitivity } \\
\text { thresholds } \\
\text { (dB) }\end{array}$ & $\begin{array}{l}\text { Fixation } \\
\text { areas } \\
(\operatorname{logBCEA})\end{array}$ \\
\hline 0 (baseline) & $\begin{array}{l}28.48 \\
(28.09 \text { to } \\
28.87)\end{array}$ & $\begin{array}{l}-0.28(- \\
0.39 \text { to }- \\
0.17)\end{array}$ & $\begin{array}{l}7.8(3.61 \\
\text { to } 11.87)\end{array}$ & $\begin{array}{l}0.22(- \\
0.15 \text { to } \\
0.65)\end{array}$ & $\begin{array}{l}28.16 \\
(27.63 \text { to } \\
28.81)\end{array}$ & $\begin{array}{l}-0.31(- \\
0.58 \text { to }- \\
0.08)\end{array}$ \\
\hline 5 & $\begin{array}{l}+0.09(- \\
0.17 \text { to }\end{array}$ & $\begin{array}{l}-0.06(- \\
0.14 \text { to }\end{array}$ & & & & \\
\hline
\end{tabular}




\begin{tabular}{|c|c|c|c|c|c|c|}
\hline & $\begin{array}{l}0.35 \\
p=0.52)\end{array}$ & $\begin{array}{l}0.01 \\
p=0.11)\end{array}$ & & & & \\
\hline 10 & $\begin{array}{l}+0.28 \\
(0.00 \text { to } \\
0.56 \\
p=0.04)\end{array}$ & $\begin{array}{l}+0.04 \text { (- } \\
0.03 \text { to } \\
0.12, \\
p=0.22)\end{array}$ & & & $\begin{array}{l}+1.12(0.4 \\
\text { to } 1.9 \\
p=0.002)\end{array}$ & $\begin{array}{l}+0.07(- \\
0.07 \text { to } \\
0.25 \\
p=0.38)\end{array}$ \\
\hline 15 & $\begin{array}{l}-0.11(- \\
0.35-0.20, \\
p=0.44)\end{array}$ & $\begin{array}{l}-0.03(- \\
0.10 \text { to } \\
0.05 \\
p=0.43)\end{array}$ & & & & \\
\hline 20 & $\begin{array}{l}+0.11(- \\
0.17 \text { to } \\
0.39 \\
p=0.42)\end{array}$ & $\begin{array}{l}+0.00(- \\
0.07 \text { to } \\
0.09 \\
p=0.91)\end{array}$ & $\begin{array}{l}-0.01(- \\
0.03 \text { to } \\
0.01 \\
p=0.43)\end{array}$ & $\begin{array}{l}+0.00(- \\
0.00 \text { to } \\
0.01, \\
\mathrm{p}=0.27)\end{array}$ & $\begin{array}{l}-0.15 \text { (- } \\
0.59 \text { to } \\
0.20 \\
p=0.42)^{*}\end{array}$ & $\begin{array}{l}+0.06(- \\
0.10 \text { to } \\
0.07 \\
p=0.48)\end{array}$ \\
\hline 30 & $\begin{array}{l}+0.13(- \\
0.13 \text { to } \\
0.40 \\
p=0.33)\end{array}$ & $\begin{array}{l}+0.07 \text { (- } \\
0.01 \text { to } \\
0.15 \\
p=0.06)\end{array}$ & & & & \\
\hline
\end{tabular}

Table 2: Average changes in sensitivity and fixation area with increasing adaptation time. Initial sensitivity and fixation area is shown in the $\mathbf{0}$ (baseline) row. All other rows display difference from the baseline and the associated $p$ value as calculated by the mixed effects model apart from *this cell, which displays measured difference between 10 and 20 minutes and the associated $p$ value. A positive number indicates an increase in sensitivity or in fixation area. Where $p<0.01$ the cell has been emboldened.

In healthy participants, average threshold sensitivity was as follows (Table 1). Effects of adaptation time on average fixation area was as follows: (Table 2, Figure 1.) We found no effect of adaptation time on threshold sensitivity or fixation area. Histograms plotted to 
examine distribution of data points found no change in spread of threshold sensitivities between 0 and 20 minutes in either the healthy participant or choroideremia group (Figure 2).

Pointwise sensitivity plots also showed no consistent pattern of change, either in any specific sector, or between central and peripheral points with increasing adaptation time. On visual inspection, while the 10 and 30 minute plots appear to show more depressed central responses than 0 and 5 minutes, this change is not consistent amongst 15 or 20 minutes. Furthermore, considering the spatial distribution of rods compared to cones, we would expect to see any significant rod contribution reflected in peripheral sensitivity changes. However, there is little change in peripheral sensitivities as adaptation time is increased. (Figure 3).

In choroideremia patients, average threshold sensitivity at 0 minutes was as follows: (Table 1). Again, we found no effect of 20 minutes of adaptation time on threshold sensitivity or fixation area (Table 2, Figure 4a.)

In healthy participants who had undergone 3 minutes of bright light exposure (direct retinal ophthalmoscopy) prior to dark adaptation, average threshold sensitivity and fixation area was as follows: (Table 1). Threshold sensitivity at 10 minutes was significantly better than 0 minutes but there was no difference between 10 and 20 minutes. There was no significant difference between fixation area at 0, 10 or 20 minutes (Table 2, Figure 4b.)

A post-hoc power analysis using the power calculation package (13) for generalised linear mixed models in R studio (simr function, R studio Version 1.0.44, supported by $\mathrm{R}$ version 3.2.2.) with $p=0.05$ and effect size $1.3 \mathrm{~dB}$, found our model had a predicted power of $100 \%$ (99.63-100\%) for the healthy participants, 95\% for the bright light group (94.14-96.7\%), and $100 \%(99.63-100 \%$ for the choroideremia group. The effect size of $1.3 \mathrm{~dB}$ was chosen as the lowest clinically significant value that falls outside of the MAIA inter-test reliability range (14). This power calculation should be interpreted with caution (15). 


\section{DISCUSSION}

It is well established that cone adaptation is significantly more rapid than rods due to biological regeneration of the cone opsins following a faster process than rhopdopsin. Cones fully adapt in under 8 minutes even after intense photoreceptor bleaching, with faster adaptation occurring with lower intensity of prior light exposure (8). The finding that central retinal responses to static light stimuli appear predominantly cone-mediated would therefore support the hypothesis that prolonged dark adaptation (i.e. beyond 8 minutes) would not improve mesopic microperimetry responses. The hypothesis of our study, therefore, was that adaptation time beyond 10 minutes would not confer improved mesopic microperimetry responses in healthy participants after exposure to ambient or to bright light. For clarity, we note that due to the differences in background illumination and stimuli intensity, our results are not generalizable to scotopic microperimeters (e.g. the SMAIA (Centervue, Italy) and MP-1S scotopic (Nidek, Italy).

The results of our study support the premise that central macula responses to static threshold white light stimuli under mesopic settings are predominantly cone-mediated. We found that the central threshold sensitivity and fixation stability was maintained in healthy participants exposed to ambient room light only, which is consistent with a rapid cone adaptation time after moderate light exposure. While we found a statistically significant increase in threshold sensitivity at 10 minutes of $0.28 \mathrm{~dB}$, we are inclined to interpret this result as clinically insignificant for the following reasons. Firstly, the $p$ value was borderline even for statistical significance $(p=0.04)$. Secondly, inter-test reliability in healthy participants and in patients with choroideremia on the MAIA microperimeter has been measured at approximately $1.3-1.5 \mathrm{~dB}$, over 5 times the magnitude of the result we found $(5$, 14). After more intense light exposure (direct ophthalmoscopy), we found central threshold sensitivity dropped but had fully recovered by 10 minutes of adaptation time, corresponding to the cone recovery curve. There was no further improvement in performance in either group at 20 minutes, when rods would be expected to be at high sensitivity, indicating there is negligible effect of rod input on central field mesopic microperimetry performance. 
The question of whether mesopic retinal responses to white light are predominantly conemediated or rod-mediated has been addressed in a number of animal and human studies (9, 11, 16). The MAIA microperimeter, the MP-1 and the MP-3 microperimeters (Nidek), provide a background illuminance of $1.3 \mathrm{~cd} / \mathrm{m}^{2}$. A recent study by Simunovic examining central retinal spectral sensitivities under mesopic conditions of $1.3 \mathrm{~cd} / \mathrm{m}^{2}$ suggested that a predominantly non-opponent $\mathrm{M}+\mathrm{L}$ cone response, with $\mathrm{S}$ cone contribution, is seen in the central field (up to 10 degrees from fixation), while there is evidence of mixed rod/cone responses in the peripheral field (over 15 degrees) (11). There is further support for a predominant cone response at these illuminance levels from Hwang et al, who found that in the central $10^{\circ}$ of viewing field, spectral sensitivity patterns followed a rod-dominant response at $0.04 \mathrm{~cd} / \mathrm{m}^{2}$, became cone-dominant at $0.4 \mathrm{~cd} / \mathrm{m}^{2}$, and followed a pure photopic cone response at $1.8 \mathrm{~cd} / \mathrm{m}^{2}(15)$. The work of Crossland et al comparing spectral sensitivities using the MP-1 microperimeter (Nidek) provides further evidence for cone-dominated mesopic responses (9).

However, it is also clear that rod input modifies cone responses in mesopic settings to a variety of stimuli, at the cellular and perceptual level. There is evidence of rod activation leading to suppression of cone responses in mesopic settings via direct rod-cone signalling, and vice versa (17). There is also evidence of summation of rod and cone responses at the cone bipolar cell level and the LGN (17-19). Hence, while central retinal responses appear predominantly cone-mediated, absent or abnormal rod inputs may still theoretically influence the microperimetry response.

Choroideremia is a disease that predominantly affects rods, particularly in the earlier stages. However, cone function appears to be preserved remarkably late in the disease course, despite severe structural changes and loss of rod function $(20,21)$. We therefore hypothesised that these results would be applicable to our group of choroideremia participants. The fact that we found no difference in retinal sensitivity thresholds between 0 and 20 minutes of adaptation in choroideremia patients further supports the theory that central retinal responses are predominantly cone-mediated, and suggests that any rod inputs under mesopic conditions confer negligible effects on perceptual thresholds as measured by microperimetry. This suggests our findings are applicable to participants with rod-cone dystrophies where cone function is known to be relatively preserved. Of interest, 
however, is that many of the choroideremia participants verbally reported finding the test more difficult without dark adaptation, despite no statistically significant difference in outcomes.

It has been noted that microperimetry responses have been found to decrease with age, while central cone responses as measured by mfERG have been found in one study to be preserved with age (22). One interpretation of this might be that microperimetry responses must be at least partly rod-mediated, otherwise one would expect preservation of responses with age in accordance with mfERG measurements. However, the participants in the Tam et al study were all pseudophakic, chosen to exclude the effects of media opacity on mfERG responses. Media opacity is known to affect microperimetry and peripheral automated perimetry responses (23), and in studies of mfERG responses in older adults where pseudophakia was not a requirement, mfERG latency and amplitude have been found to decrease with age, which would account for the observed decrease in microperimetry responses with age $(24,25)$. Furthermore, it has been noted that colour vision declines with age, which corresponds to deterioration of cone responses (26).

It has also been suggested that rod contribution in mesopic conditions may fall beyond the dynamic detection range measurable by the MAIA microperimeter. It is indeed possible perceptual thresholds as measured by the MAIA are not sensitive enough to pick up rod contributions. However, normal thresholds in MAIA microperimetry are not close to the ceiling threshold of $36 \mathrm{~dB}$, with most studies of normal eyes finding with mean sensitivities of $29.78 \mathrm{~dB}, 27.12 \mathrm{~dB}$, and $26.9 \mathrm{~dB}(27,28)$. Our study corresponds to these lower sensitivities, with an average threshold sensitivity of 28.48 in the healthy participants at 0 minutes of dark adaptation. We also see no change in the choroideremia participants, for whom the ceiling argument could not be made. We therefore suggest our work offers evidence to supports the existing body of evidence that mesopic vision is cone-dominated.

Along with our previous work showing that pupil dilation does not significantly affect MAIA microperimetry outcomes (12), we hope to have established useful clinical guidance on standard requirements for microperimetry performance. In conclusion, we recommend that dark adaptation before mesopic microperimetry testing is not necessary after exposure to ambient light in either healthy participants or in patients with retinal dystrophies where 
cone function is known to be relatively preserved. We recommend a period of 10 minutes of dark adaptation before microperimetry testing after exposure to a bright light stimulus, such as retinal photography or slit lamp examination. While pupil dilation does not appear to significantly alter threshold sensitivities, we recommend that where reproducibility is vital (e.g. a clinical trial) that patients be tested consistently either dilated or undilated. While our work was carried out on the MAIA microperimeter, we consider it probable that the same recommendations would apply to other mesopic microperimeters with similar background illuminance and dynamic range (for example, the MP-1 and MP-3, Nidek) (29, 30). Further work looking at effect of light levels and dark adaptation on mesopic microperimetry responses in participants with macular dystrophies known to affect cone function and adaptation times, such as AMD (31) would be helpful to give guidance in participants with cone pathologies. 


\section{Acknowledgements}

With thanks to Dr Chris Jewell of Lancaster University for statistics advice.

\section{Competing interests}

None to declare

\section{Funding}

Financial: This work was funded by the Oxfordshire Health Services Research Committee (OHSRC) Grant Ref 1173 and supported by the National Institute for Health Research (NIHR) Oxford Biomedical Research Centre based at Oxford University Hospitals NHS Trust and University of Oxford.

The views expressed are those of the authors and not necessarily those of the NHS, the NIHR or the Department of Health. The sponsor and funding organisation had no role in the design or conduct of this research.

\section{Contributorship statement}

Each of the named authors (RC Han, J Han, J Gray, RE MacLaren, JK Jolly) has made substantial contributions to the work, meeting the criteria for authorship.

RC Han, JK Jolly and RE MacLaren were responsible for the conception and design of the work.

RC Han, J Han, J Gray, JK Jolly were responsible for the acquisition of data.

RC Han, JK Jolly were responsible for the analysis and interpretation of data.

RC Han, JK Jolly were responsible for drafting of the work.

All authors were involved in revising the work critically, giving final approval of the version published, and in agreement to be held accountable for all aspects of the work.

\section{REFERENCES}


1. Maclaren RE, Groppe M, Barnard AR, et al. Retinal gene therapy in patients with choroideremia: initial findings from a phase 1/2 clinical trial. Lancet. 2014;6736(13):19. doi:10.1016/S0140-6736(13)62117-0.

2. Edwards TL, Groppe M, Jolly JK,et al. Correlation of Retinal Structure and Function in Choroideremia Carriers. Ophthalmology. 2015:1-3.

doi:10.1016/j.ophtha.2014.12.036.

3. $\mathrm{Wu}$ Z, Ayton LN, Guymer RH, et al. Intrasession test-retest variability of microperimetry in age-related macular degeneration. Invest Ophthalmol Vis Sci. 2013;54(12):7378-7385. doi:10.1167/iovs.13-12617.

4. Orzalesi N, Miglior S, Lonati C,et al. Microperimetry of localized retinal nerve fiber layer defects. Vision Res. 1998;38(5):763-771. doi:10.1016/S0042-6989(97)00171-5.

5. Jolly JK, Kanmin X, Edwards TL et al. Characterizing the Natural History of Visual Function in Choroideremia Using Micropeimetry and Multimodal Retinal Imaging. IOVS. 2017; 58:(12). 5575-5583 doi: 10.1167/iovs.12-22486

6. Lee P, Crumbliss K. Low Vision Rehabilitation of Stargardt's Disease with the Aid of Microperimetry and Prism Relocation. AAOpt 2016

7. MAIA Macular Integrity Assessment. Accessed May 2015. Available from: https://www.haag-

streit.com/fileadmin/HaagStreit UK/Downloads/Centervue downloads/MAIA clinica 1 handbook.pdf

8. S. Hecht, C. Haig, A.M. Chase. The influence of light adaptation on subsequent dark adaptation of the eye. Journal of General Physiology. 1937. 20. 831-850

9. Crossland MD, Tufnail A, Rubin GS. Mesopic Microperimetry Measures Mainly Cones; Dark-adpted Microperimetry Measures Rods and Cones. ARVO Annual Meeting Abstract. 201253 
10. McCulloch DL, Marmor MF, Brigell MG, et al. ISCEV Standard for full-field clinical electroretinography (2015 update). Bach M. Doc Ophthalmol. 2015 Feb: 130 (1): 1-12 doi 10.1007/s10633-014-9473-7

11. Simunovic, MP, Moore AT, MacLaren RE. Selective Automated Perimetry Under Photopic, Mesopic, and Scotopic Conditions: Detection Mechanisms and Testing Strategies. Translational Vision Science and Technology. 2016. 20;5 (3): 10.

12. RC Han, Jolly JK, Xue K et al. Effects of pupil dilation on MAIA microperimetry. Clin Exp Ophthalmol. 2017 Jul;45(5):489-495. doi: 10.1111/ceo.12907.

13. P Green, CJ MacLeod. SIMR: an R package for power analysis of generalized linear mixed models by simulation. Methods in Ecology and Evolution. 2016. 7; 493-498. doi: 10.1111/2041-210X.12504

14. Dimopoulos IS, Tseng C, MacDonald IM. Microperimetry as an Outcome Measure in Choroideremia Trials: Reproducibility and Beyond. iOVS. 2016. 57; 4151-4161. doi:10.1167/iovs.16-19338

15. Heonig JM. 'The Abuse of Power: The pervasive fallacy of power calculations for data analysis.' 2001. The American Statistician 55(1), 19-24.

16. Hwang J, Lee DH, Park S, et al. Measurement of rod and cone effects in mesopic visual sensitivity by varying viewing field. J. Opt. Soc. Am A Opt Image Sci Vis. 2013. $1 ; 30$ (10); 1929-36

17. Zele AJ, Maynard ML, Feigl B. Rod and cone pathway signaling and interaction under mesopic conditions. J Vis. 201313 (1)

18. Krizaj D. Mesopic state: cellular mechanisms involved in pre- and post synpatic mixing of rod and cone signals. Microsc Res Tech 2000 1;50(5) 347-59

19. Zele AJ, Cao DC. Vision under mesopic and scotopic illumination. Front Psychol. 2014; $5 ; 1594$.

20. Dimopoulos IS, Freund PR, Knowles JA, et al. The Natural History of Full-Field Stimulus Threshold Decline in Choroideremia. Retina. 2017 DOI 10.1097 PMID 28800019

21. Sun LW, Johnson RD, Williams V et al. Multimodal Imaging of Photoreceptor Structure in Choroideremia. PloS One. 201611 (12): e0167526 
22. Tam WK, Chan H, Brown B et al. Aging and mfERG topography. Eye (Lond) 2006. 20 (1): 18-24.

23. Georgiev S, Palkovits S, Ullich M, et al. Poster abstract. Impact of cataract surgery on retinal sensitivity measurements of a fundus-related perimeter (Microperimetry Microperimeter 3) in patients with different types of cataract. Presented ESCRS 2016.

24. Tzekov RT, Gerth C, Werner JS. Senescence of human multifocal electroretinogram components: a localized approach. Graefes Arch Clin Exp Ephthalmol. 2004; 242. 549560 .

25. Nabeshima T. The effects of aging on the multifocal electroretinogram. Jpn J Ophthalmol. 2001; 45: 114-115.

26. Paramei GV. Color discrimination across four life decades as assessed by the Cambridge Colour Test. Journal of the Optical Society of America. 2012. 29 (2). A290A297.

27. Sato S, Hirooka K, Baba T et al. Correlation between the ganglion cell-inner plexiform layer thickness measured with cirrus HD-OCT and macular visual field sensitivity measured with microperimetry. Invest Ophthalmol Vis Sci. 2013; 54 (4):3046-3051

28. Martinez-Costa A, Pinero DP, Perez-Cambrodi RJ. Reliability and intersession agreement of microperimetric and fixation measurements obtained with a new microperimeter in normal eyes. Curr Eye Res. 2016; 41 (3): 400-409

29. Nidek MP-1 manual. Accessed May 2018. Available from: http://usa.nidek.com/products/microperimeter-mp-1s/

30. Nidek MP-3 manual. Accessed May 2018. Available from: http://usa.nidek.com/microperimeter-mp-3/

31. Gaffney AJ, Binns AM, Margrain TH. Topography of cone dark adaptation deficits in age-related maculopathy. Optom Vis Sci. 2011.88 (9) 1080-7

\section{FIGURE LEGENDS}

Figure 1a. Person plot showing effect of dark adaptation time (minutes) on threshold sensitivity changes $(\mathrm{dB})$ in healthy volunteers as calculated by the mixed effects model. Adaptation time in minutes is displayed on the left-hand $x$-axis and represented by the 
dark grey horizontal bars extending to the left. Average threshold sensitivity is displayed on the right-hand $x$-axis and is represented by the light grey horizontal bars extending to the right, corresponding to each category of adaptation time. Error bars show standard errors of the mean. No clinically significant difference was seen between times.

Figure 1b. Fixation area ( $\operatorname{logBCEA})$ represented by shaded circles plotted against length of dark adaptation in minutes ( $x$ axis). The area of each circle represents fixation area in degrees $^{2}$. Each circle is labelled with the corresponding logBCEA value. A black circle of size 1 degrees $^{2}(0 \operatorname{logBCEA})$ is provided for reference size. There was no statistically significant difference in fixation area at any time point compared to 0 minutes. 
Figure 2. Histograms showing spread of threshold sensitivities for healthy participants (left) and choroideremia patients (right) at $\mathbf{0}$ (top) and 20 minutes (bottom) of adaptation. In each graph the $y$ axis represents number of participants while the $x$ axis represents threshold sensitivity $(\mathrm{dB})$. There is no apparent change in distribution of data points. 
Figure 3. Pointwise sensitivity plots showing average threshold sensitivities at each of the individual 37 points of the MAIA grid, at each level of adaptation time. Averages were taken from all $\mathbf{4 0}$ healthy participant eyes. The plots are colour-coded for easy visual inspection, with each $4 \mathrm{~dB}$ sensitivity interval represented by a different colour. There is no consistent pattern of change between central and peripheral points with increasing adaptation time. 
Figure 4. Effect of dark adaptation time (minutes) on mean threshold sensitivity (dB) and mean fixation area ( $\log B C E A)$ in choroideremia patients (figure 2a) and in healthy volunteers after exposure to 3 minutes of bright light (figure $2 \mathrm{~b}$ ). Threshold sensitivity is represented by bars: error bars represent standard errors of the mean. Mean fixation area is represented by circles plotted against time on the $x$ axis: circle area corresponds to fixation area in degrees ${ }^{2}$. Each circle is labelled with its corresponding logBCEA value. A black circle of size 1 degrees $^{2}(0 \log B C E A)$ is provided for reference size.

Figure 4a. For choroideremia patients there was no significant difference between 0 and 20 minutes for either threshold sensitivity $(p=0.43)$ or fixation area $(p=0.27)$.

Figure $4 \mathrm{~b}$. For healthy volunteers exposed to bright light for $\mathbf{3}$ minutes, there is a significant difference in sensitivity at 10 minutes of dark adaptation $(p=0.002)$, but no difference between 10 and $\mathbf{2 0}$ minutes. There is no significant difference in fixation stability between times. 
56

57

58

59 
$1 a$

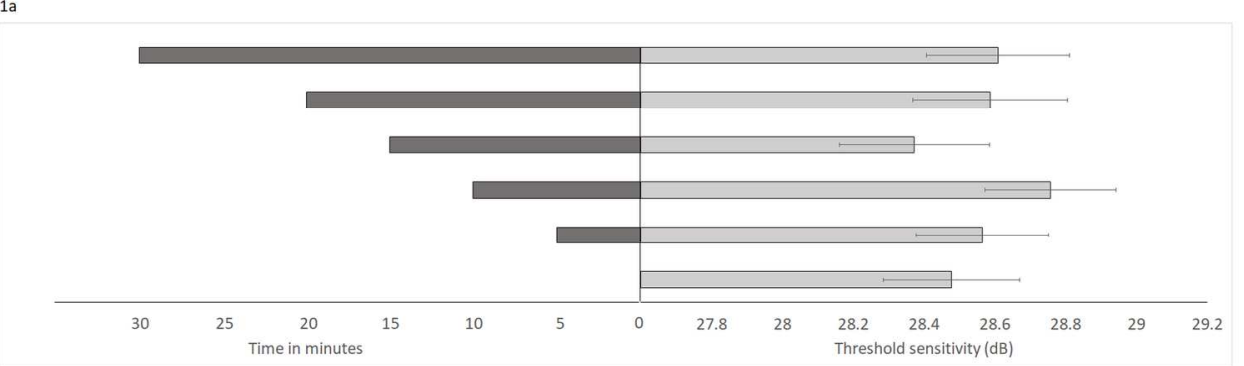

16

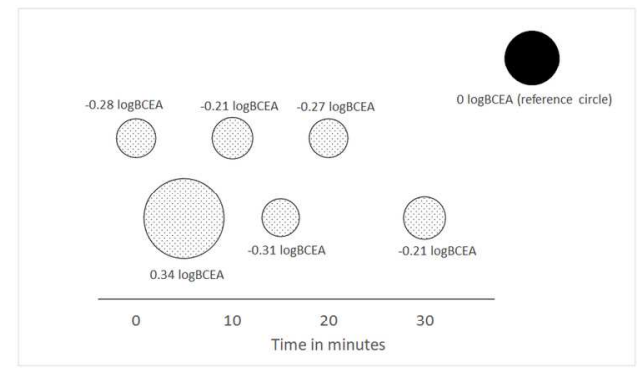

Figure 1a. Person plot showing effect of dark adaptation time (minutes) on threshold sensitivity changes $(\mathrm{dB})$ in healthy volunteers as calculated by the mixed effects model. Adaptation time in minutes is displayed on the left-hand $\mathrm{x}$-axis and represented by the dark grey horizontal bars extending to the left. Average threshold sensitivity is displayed on the right-hand $\mathrm{x}$-axis and is represented by the light grey horizontal bars extending to the right, corresponding to each category of adaptation time. Error bars show standard errors of the mean. No clinically significant difference was seen between times. Figure 1b. Fixation area ( $\log B C E A)$ represented by shaded circles plotted against length of dark adaptation in minutes ( $x$ axis). The area of each circle represents fixation area in degrees 2 . Each circle is labelled with the corresponding $\operatorname{logBCEA}$ value. A black circle of size 1 degrees2 ( 0 logBCEA) is provided for reference size. There was no statistically significant difference in fixation area at any time point compared to 0 minutes

$171 \times 117 \mathrm{~mm}(300 \times 300$ DPI $)$ 

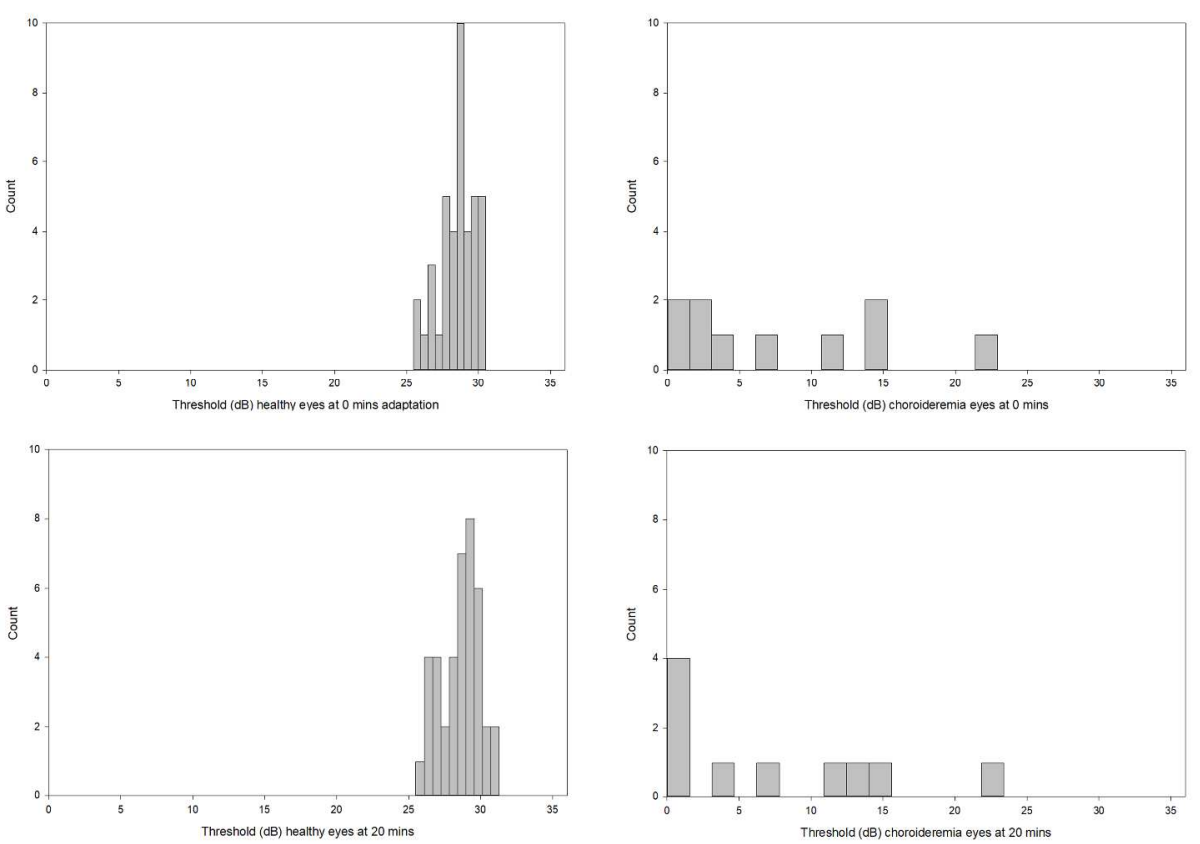

Figure 2. Histograms showing spread of threshold sensitivities for healthy participants (left) and choroideremia patients (right) at 0 (top) and 20 minutes (bottom) of adaptation. In each graph the y axis represents number of participants while the $x$ axis represents threshold sensitivity $(d B)$. There is no apparent change in distribution of data points.

$212 \times 149 \mathrm{~mm}(300 \times 300$ DPI $)$ 

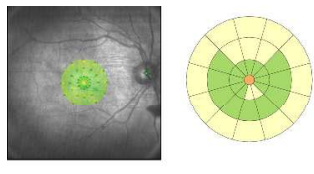

wann outpau

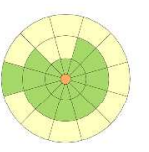

5 mirtes

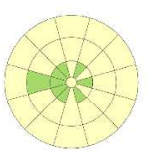

10 minutus

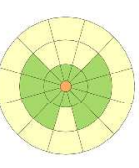

ismineses

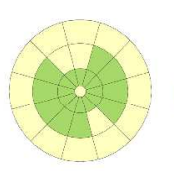

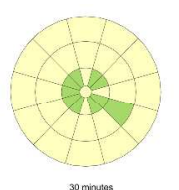

Threshold
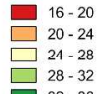

Logond

Figure 3. Pointwise sensitivity plots showing average threshold sensitivities at each of the individual 37 points of the MAIA grid, at each level of adaptation time. Averages were taken from all 40 healthy participant eyes. The plots are colour-coded for easy visual inspection, with each $4 \mathrm{~dB}$ sensitivity interval represented by a different colour. There is no consistent pattern of change between central and peripheral points with increasing adaptation time.

$664 \times 101 \mathrm{~mm}$ (300 x 300 DPI) 


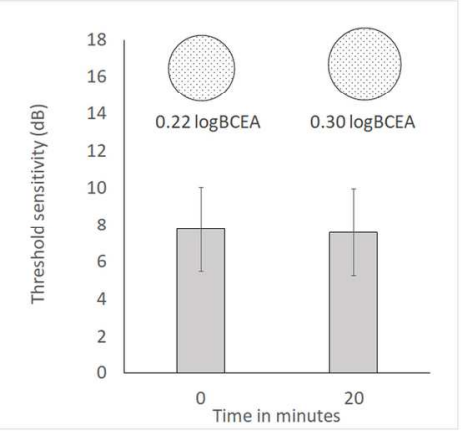

b

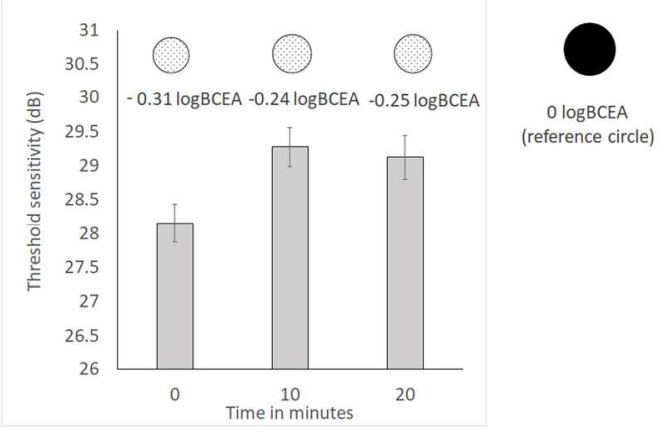

Figure 4. Effect of dark adaptation time (minutes) on mean threshold sensitivity (dB) and mean fixation area $(\operatorname{logBCEA})$ in choroideremia patients (figure 2a) and in healthy volunteers after exposure to 3 minutes of bright light (figure $2 \mathrm{~b}$ ). Threshold sensitivity is represented by bars: error bars represent standard errors of the mean. Mean fixation area is represented by circles plotted against time on the $\mathrm{x}$ axis: circle area corresponds to fixation area in degrees2. Each circle is labelled with its corresponding logBCEA value. A black circle of size 1 degrees2 ( 0 logBCEA) is provided for reference size.Figure $4 a$. For choroideremia patients there was no significant difference between 0 and 20 minutes for either threshold sensitivity $(p=0.43)$ or fixation area $(p=0.27)$. Figure $4 b$. For healthy volunteers exposed to bright light for 3 minutes, there is a significant difference in sensitivity at 10 minutes of dark adaptation $(p=0.002)$, but no difference between 10 and 20 minutes. There is no significant difference in fixation stability between times.

$157 \times 65 \mathrm{~mm}(300 \times 300 \mathrm{DPI})$ 